\title{
The Ranschburg effect: Stimulus variables and scoring criterion*
}

\author{
STEVEN P. MEWALDT $\dagger$ and JAMES V. HINRICHS \\ University of Iowa, Iowa City, Iowa 52242
}

\begin{abstract}
The influence of stimulus variables on recall of intraserially repeated items was investigated with a parametric manipulation of the rate of presentation $(.4, .8$, or $1.6 \mathrm{sec} / \mathrm{item})$, modality of presentation (auditory or visual), and sequence length ( 7 or 10 items long). The results indicated that the Ranschburg effect, poorer recall of repeated items than of corresponding control items, is relatively insensitive to stimulus manipulations. The Ranschburg effect was found to be localized primarily at the position of the second occurrence of the repeated item. The influence of the repeated items did not generalize to the other (nonrepeated) items of the sequence. Differences in the Ranschburg effect as a function of the scoring criterion were discussed. The results were interpreted as being consistent with a guessing bias interpretation of the Ranschburg effect.
\end{abstract}

When Ss are presented with a short sequence of items containing at least one repeated item and are asked to recall the sequence in serial order, the Ranschburg effect may be observed. Poorer recall of either the repeated items specifically or of the experimental list in general, when compared to recall of a control sequence which contains no repeated items, defines the Ranschburg effect (see Jahnke, 1969b, for a comprehensive review). While being a necessary prerequisite, repetition of an item in a sequence is not a sufficient condition to produce the effect. There are at least four important variables which delimit the Ranschburg effect: (a) the position of the repeated items in the sequence (Crowder, 1968a; Crowder \& Melton, 1965; Jahnke \& Melton, 1968; Obonai \& Tatsuno, 1954; Wickelgren, 1965, 1966 ), (b) the acoustic similarity of the stimuli (Jahnke \& Melton, 1968), (c) the type of recall task employed (Harris \& Jahnke, 1972; Jahnke, 1970; Wolf \& Jahnke, 1968), and (d) the stimulus set size (Hinrichs, Mewaldt, \& Redding, in press; Jahnke, 1972).

Because with a few exceptions (Crowder, 1968b; Jahnke, 1972; Obonai \& Tatsuno, 1954; Wickelgren, 1965) recent studies demonstrating the Ranschburg effect have employed essentially the same restricted procedure, there is doubt about the effective domain of the phenomenon. The usual procedure for testing the Ranschburg effect consists of employing a stimulus set of random digits or a limited set of acoustically distinct letters, a sequence length of seven or eight items, a presentation rate of two or three items/sec, and a testing method requiring recall of all of the presented stimuli.

*This research was supported by National Institute of Mental Health Grant MH 16362 awarded to the second author. This paper is based on a thesis completed by the first author under the direction of the second author and submitted to the University of Iowa in partial fulfillment of the requirements of the MA degree.

$\nmid$ Requests for reprints should be sent to Steven P. Mewaldt, Department of Psychology, University of Iowa, Iowa City, lowa 52242 .
Consequently, one purpose of the present study was to attempt to extend the known boundary conditions of the Ranschburg effect by a parametric manipulation of three stimulus variables: (a) rate of presentation $(.4, .8$, or $1.6 \mathrm{sec} /$ item), (b) modality of presentation (auditory or visual), and (c) sequence length (7 or 10 items long).

While the Ranschburg effect appears to be most sensitive to output variables (e.g., Crowder, 1968b; Jahnke, 1969a, b), further investigation of the stimulus dimension is warranted. While some previous research suggests that rate of presentation may influence the Ranschburg effect (Ranschburg, 1902, cited in Obonai \& Tatsuno, 1954; Turley, 1906; Wickelgren, 1965), there appears to be no evidence indicating the effect of the other two variables. Wickelgren (1965) did manipulate sequence length while studying several patterns of intraserial repetition. However, in reporting his results he collapsed across sequence lengths, so the effect for each individual length cannot be determined. All other modern studies have employed either a seven- or eight-item sequence length.

Aside from the purely empirical interest in the effective domain of the Ranschburg effect, the present experiment permitted a test of two questions of theoretical concern regarding the cause of the effect. First, there is some uncertainty about the strength of the Ranschburg effect as a function of whether serial position or free recall scoring is employed. A response is correct by a serial position criterion only if it occurs in its correct serial position in the recall sequence; a stimulus item is correct by a free recall criterion if it occurs any place in the response sequence. Jahnke (1969a) has argued that the free recall criterion is the more appropriate method of scoring data on the Ranschburg effect because this method appears to be more sensitive to the effect than does serial position scoring. The second question was concerned with a separation of two aspects of the Ranschburg effect: (a) the effect of repetition on recall of the repeated items themselves, and (b) the effect of the repetition on 
recall of the other (nonrepeated) items of the sequence. Analysis of the first aspect is achieved by comparing recall performance on only the critical items (critical items are the repeated items in experimental sequences and the items occupying the corresponding serial position in the control sequences). The second aspect is measured by comparing performance on corresponding nonrepeated items in the two types of sequences. The question of concern is whether the decrement in performance on repeated items generalizes to the rest of the sequence in which the critical items are embedded.

\section{METHOD}

\section{Materials and Apparatus}

A 7-digit and a 10-digit set of sequences consisting of 28 sequences each were constructed from a table of random permutations of the digits 0-9 (Moses \& Oakford, 1963), with the restriction that no sequence contain a numerically ascending or descending series of digits of length greater than two. From these sets, 20 sequences were selected to serve as control sequences. The remaining 8 sequences were employed on practice trials. Experimental sequences were constructed from the control sequences by the following method. For 10 sequences, the fifth digit in the sequence was changed to the digit found in the second position. For the other 10 sequences, the sixth digit was changed to correspond to that of the third position.

Lists of sequences were formed by randomizing the 40 test sequences with the following restrictions: (a) adjacent experimental sequences could not have the same repetition structure, (b) the same digit could not serve as the repeated digit in two consecutive sequences, (c) adjacent sequences could neither start nor end with the same digit, (d) no sequence could start with the same digit that the preceding sequence had ended with, and (e) the two forms of a particular sequence were separated by at least 8 intervening sequences (mean $=16$ ), so there should be little facilitation from the first to aid recall of the second. In addition, the two types of forms occurred first or second equally of ten.

The stimuli were presented visually by means of a Bina-View display controlled by a digital logic system and paper tape reader. Auditory stimuli were recorded and presented by a tape recorder. Stimulus duration was approximately equated for the two modalities by having the screen of the Bina-View turn blank $250 \mathrm{msec}$ after each digit was presented. This was found to be the average duration of the auditory stimuli recorded by $\mathrm{E}$.

\section{Design}

A 2 by 2 by 3 by 2 by 2 factorial design was employed with two within- $S$ factors, sequence length and position of the critical items, and three between-S factors, modality, rate of presentation, and order of presentation of the two sequence lengths. Sequences were either 7 or 10 digits long and were presented at a rate of $.4, .8$, or $1.6 \mathrm{sec} /$ item.

\section{Procedure}

The Ss receiving stimuli in the visual modality initiated each sequence by pressing a telegraph key placed on the table in front of them. Following the last digit in the sequence, a red blank appeared on the screen as a cue for recall. Recall was spoken and Ss were instructed to recall the items in the order in which they were presented. When uncertain of an item, Ss were instructed to guess or say "blank" at that position in the sequence. Tape recordings of Ss' responses were made and were used to check E's written records. The Ss receiving stimuli in the auditory mode used the same procedure, except that they initiated each sequence by saying "ready" and the cue for recall was a brief "click" at the end of a sequence. The duration of the intersequence interval was determined by $S$ and varied with the time required to respond; the interval averaged under $10 \mathrm{sec}$.

In both modalities, eight practice sequences preceded each of the test lists. Following completion of the first list, a brief rest period was given before starting the new length sequence. Presentation of the sequence length variable was counterbalanced across Ss.

\section{Subjects}

The Ss were 36 male and 60 female introductory psychology students fulfilling a course requirement at the University of Iowa. Three males and five females were assigned to each of the 12 between-S conditions of the experiment. Conditions were randomized in blocks and Ss were assigned to each condition in their order of appearance in the laboratory.

\section{RESULTS}

Both critical and noncritical items were analyzed separately with free recall and serial position scoring. Because of the large number of factors involved in the present design, the probability of obtaining significant effects by chance was greatly increased. Consequently, to reduce the probability of a Type I error, a minimum alpha level of .01 was adopted for all analyses.

\section{Critical Item Analysis}

\section{Free Recall Scoring}

Performance on critical items in Serial Positions 2 and 3 was combined for the first occurrence of a critical item, and performance on Positions 5 and 6 was combined for the second. Single occurrences of a repeated item in a response sequence, i.e., when a repeated item was recalled only once in the response sequence, were assigned to the nearest of the two stimulus serial positions in which the repeated item had occurred. The means and standard errors for each condition are presented in Table 1.

The Ranschburg effect, defined in terms of critical items, is lower recall of experimental items than of control items. The mean number of repeated items recalled was 31.0. The mean number of control items was 35.2. The difference was significant $[F(1,84)=$ $203.58, p<.001]$. The strength of this effect was also indicated by the fact that the Ranschburg effect per se was not significantly reduced by any of the manipulations of this experiment, i.e., it did not interact with any variable.

The above definition of the effect, however, does not take into account the locus of the effect. A Ranschburg effect can result if only one of the repeated items is 
Table 1

Mean Number of Critical Items Correct and Corresponding Standard Errors Using Free Recall Scoring

\begin{tabular}{|c|c|c|c|c|c|c|c|c|c|c|c|c|c|c|}
\hline \multirow{3}{*}{$\begin{array}{c}\text { Presen- } \\
\text { tation } \\
\text { Mode } \\
\end{array}$} & \multirow{3}{*}{$\begin{array}{c}\text { Sequence } \\
\text { Length }\end{array}$} & \multirow{3}{*}{ Score } & \multicolumn{4}{|c|}{ 4-Sec Rate } & \multicolumn{4}{|c|}{.8-Sec Rate } & \multicolumn{4}{|c|}{ 1.6-Sec Rate } \\
\hline & & & \multicolumn{2}{|c|}{ SP 2 and 3} & \multicolumn{2}{|c|}{ SP 5 and 6} & \multicolumn{2}{|c|}{ SP 2 and 3} & \multicolumn{2}{|c|}{ SP 5 and 6} & \multicolumn{2}{|c|}{ SP 2 and 3} & \multicolumn{2}{|c|}{ SP 5 and 6} \\
\hline & & & $\mathrm{E}$ & $\mathrm{C}$ & $\mathrm{E}$ & $\mathrm{C}$ & $\mathrm{E}$ & $\mathrm{C}$ & $\mathbf{E}$ & $\mathrm{C}$ & $\mathrm{E}$ & $\mathrm{C}$ & $E$ & $\mathrm{C}$ \\
\hline \multirow{2}{*}{ Auditory } & 7 & $\begin{array}{l}\text { Mean } \\
\text { SE }\end{array}$ & $\begin{array}{l}18.9 \\
.369\end{array}$ & $\begin{array}{l}19.8 \\
.140\end{array}$ & $\begin{array}{l}15.6 \\
.760\end{array}$ & $\begin{array}{l}18.8 \\
.380\end{array}$ & $\begin{array}{l}17.3 \\
.666\end{array}$ & $\begin{array}{l}19.6 \\
.150\end{array}$ & $\begin{array}{l}16.4 \\
.605\end{array}$ & $\begin{array}{l}19.5 \\
.198\end{array}$ & $\begin{array}{l}18.2 \\
.470\end{array}$ & $\begin{array}{l}19.6 \\
.216\end{array}$ & $\begin{array}{l}17.3 \\
.584\end{array}$ & $\begin{array}{l}19.4 \\
.232\end{array}$ \\
\hline & 10 & $\begin{array}{l}\text { Mean } \\
\text { SE }\end{array}$ & $\begin{array}{l}17.1 \\
.437\end{array}$ & $\begin{array}{l}18.7 \\
.303\end{array}$ & $\begin{array}{l}11.4 \\
.690\end{array}$ & $\begin{array}{l}16.1 \\
.676\end{array}$ & $\begin{array}{l}15.9 \\
.576\end{array}$ & $\begin{array}{l}17.2 \\
.574\end{array}$ & $\begin{array}{l}13.1 \\
.678\end{array}$ & $\begin{array}{l}16.7 \\
.722\end{array}$ & $\begin{array}{l}16.8 \\
.548\end{array}$ & $\begin{array}{l}17.2 \\
.472\end{array}$ & $\begin{array}{l}13.2 \\
1.00\end{array}$ & $\begin{array}{l}16.1 \\
.526\end{array}$ \\
\hline \multirow{2}{*}{ Visual } & 7 & $\begin{array}{l}\text { Mean } \\
\text { SE }\end{array}$ & $\begin{array}{l}16.6 \\
.492\end{array}$ & $\begin{array}{l}18.0 \\
.515\end{array}$ & $\begin{array}{l}12.8 \\
1.07\end{array}$ & $\begin{array}{l}15.6 \\
.606\end{array}$ & $\begin{array}{l}17.4 \\
.450\end{array}$ & $\begin{array}{l}18.6 \\
.395\end{array}$ & $\begin{array}{l}15.0 \\
.956\end{array}$ & $\begin{array}{l}16.4 \\
.667\end{array}$ & $\begin{array}{l}18.5 \\
.342\end{array}$ & $\begin{array}{l}19.4 \\
.233\end{array}$ & $\begin{array}{l}16.6 \\
.544\end{array}$ & $\begin{array}{l}18.6 \\
.292\end{array}$ \\
\hline & 10 & $\begin{array}{l}\text { Mean } \\
\text { SE }\end{array}$ & $\begin{array}{l}16.0 \\
.530\end{array}$ & $\begin{array}{l}17.2 \\
.517\end{array}$ & $\begin{array}{l}11.3 \\
.804\end{array}$ & $\begin{array}{l}14.6 \\
.558\end{array}$ & $\begin{array}{l}15.4 \\
.432\end{array}$ & $\begin{array}{l}17.4 \\
.475\end{array}$ & $\begin{array}{l}11.4 \\
.706\end{array}$ & $\begin{array}{l}15.4 \\
.458\end{array}$ & $\begin{array}{l}17.1 \\
.446\end{array}$ & $\begin{array}{l}17.2 \\
.541\end{array}$ & $\begin{array}{l}12.4 \\
1.04\end{array}$ & $\begin{array}{l}15.4 \\
.618\end{array}$ \\
\hline
\end{tabular}

recalled less often or if both critical items show the effect. Consistent with Jahnke's (1969a) results, a significant Items by Position interaction $[F(1,84)=$ $43.05, p<.001]$ was observed, revealing that the Ranschburg effect was significantly larger at the second occurrence of the repeated item than at the first. The mean difference in recall for the first critical item was 1.2 items. The difference for the second critical item was 3.0 items. Follow-up analysis indicated, however, that in both positions the Ranschburg effect was significant $(\mathrm{p}<.001)$. The Item by Position by Length interaction was also significant $[F(1,84)=9.80, p<.01]$. In the first position, the Ranschburg effect was significantly larger in the 7 -item sequences than in the 10-item sequences. In the second position, the order was reversed, as the effect was larger in the 10-item sequences ( $p<.001$ in each case). At both positions and lengths, however, the Ranschburg effect was still significant $(\mathrm{p}<.001)$. Finally, an Item by Position by Order by Mode interaction was found $[F(1,84)=7.11$, $p<.01]$. Analysis of this interaction indicated that the difference in the magnitude of the Ranschburg effect between the first and second critical items was significantly smaller for Ss receiving visual presentation with the 10 -item sequences first.

\section{Serial Position Scoring}

Table 2 presents the mean and standard errors for the number of critical items recalled in each condition of the experiment when serial position scoring was employed. The initial analysis of these scores again revealed a significant Ranschburg effect $[F(1,84)=20.67$, $p<.001]$. The mean number of critical items recalled in the experimental sequences was 25.2 items. The mean for the controls was 27.1 items. Generalizations about this effect. however, must be tempered because of two important significant interactions. First, an Item by Length interaction was observed $[F(1,84)=11.03$. $\mathrm{p}<.001]$. For the 7-item sequences, the mean difference between experimental and control performance was 3.1 items. This Ranschburg effect was significant $[F(1,84)=40.73, p<.001]$. For the 10 -item sequences, on the other hand, the mean difference was only .7 items, which was not significant $[F(1.84)=1.53$. $p>.2]$. The second significant interaction was an Item by Position interaction $[F(1,84)=17.28, p<.001]$. For the first occurrence of a critical item, the mean difference between experimental and control performance was .4 items, which was not significant $[F(1,84)=2.93, p>.05]$. For the second occurrence,

Table 2

Mean Number of Critical Items Correct and Corresponding Standard Errors Using Serial Position Scoring

\begin{tabular}{|c|c|c|c|c|c|c|c|c|c|c|c|c|c|c|}
\hline \multirow{3}{*}{$\begin{array}{c}\text { Presen- } \\
\text { tation } \\
\text { Mode }\end{array}$} & \multirow{3}{*}{$\begin{array}{c}\text { Sequence } \\
\text { Length }\end{array}$} & \multirow{3}{*}{ Score } & \multicolumn{4}{|c|}{ 4-Sec Rate } & \multicolumn{4}{|c|}{ 8-Sec Rate } & \multicolumn{4}{|c|}{ 1.6-Sec Rate } \\
\hline & & & \multicolumn{2}{|c|}{ SP 2 and 3} & \multicolumn{2}{|c|}{ SP 5 and 6} & \multicolumn{2}{|c|}{ SP 2 and 3} & \multicolumn{2}{|c|}{ SP 5 and 6} & \multicolumn{2}{|c|}{ SP 2 and 3} & \multicolumn{2}{|c|}{ SP 5 and 6} \\
\hline & & & E & $\mathrm{C}$ & $E$ & $\mathrm{C}$ & $\mathrm{E}$ & $\mathrm{C}$ & $E$ & $\mathrm{C}$ & $E$ & $\mathrm{C}$ & $E$ & $\mathrm{C}$ \\
\hline \multirow{2}{*}{ Auditory } & 7 & $\begin{array}{l}\text { Mean } \\
\text { SE }\end{array}$ & $\begin{array}{l}17.5 \\
.415\end{array}$ & $\begin{array}{l}18.7 \\
.327\end{array}$ & $\begin{array}{l}13.0 \\
.944\end{array}$ & $\begin{array}{l}16.2 \\
.907\end{array}$ & $\begin{array}{l}15.8 \\
.890\end{array}$ & $\begin{array}{l}18.1 \\
.384\end{array}$ & $\begin{array}{l}14.1 \\
.926\end{array}$ & $\begin{array}{l}17.6 \\
.492\end{array}$ & $\begin{array}{l}16.9 \\
.790\end{array}$ & $\begin{array}{l}18.2 \\
.426\end{array}$ & $\begin{array}{l}15.1 \\
.994\end{array}$ & $\begin{array}{l}17.2 \\
.568\end{array}$ \\
\hline & 10 & $\begin{array}{l}\text { Mean } \\
\text { SE }\end{array}$ & $\begin{array}{l}13.8 \\
.688\end{array}$ & $\begin{array}{l}14.2 \\
.676\end{array}$ & $\begin{array}{r}5.5 \\
.713\end{array}$ & $\begin{array}{r}7.1 \\
.822\end{array}$ & $\begin{array}{l}13.3 \\
.759\end{array}$ & $\begin{array}{l}12.1 \\
.655\end{array}$ & $\begin{array}{r}7.5 \\
.910\end{array}$ & $\begin{array}{r}8.7 \\
1.20\end{array}$ & $\begin{array}{l}14.8 \\
.746\end{array}$ & $\begin{array}{l}14.1 \\
.576\end{array}$ & $\begin{array}{r}9.5 \\
1.20\end{array}$ & $\begin{array}{l}10.0 \\
.992\end{array}$ \\
\hline \multirow{2}{*}{ Visual } & 7 & $\begin{array}{l}\text { Mean } \\
\text { SE }\end{array}$ & $\begin{array}{l}14.4 \\
.785\end{array}$ & $\begin{array}{l}14.8 \\
.911\end{array}$ & $\begin{array}{r}8.8 \\
1.13\end{array}$ & $\begin{array}{r}9.9 \\
1.15\end{array}$ & $\begin{array}{l}15.1 \\
.847\end{array}$ & $\begin{array}{l}15.9 \\
.859\end{array}$ & $\begin{array}{l}11.4 \\
1.30\end{array}$ & $\begin{array}{l}11.9 \\
1.2 ?\end{array}$ & $\begin{array}{l}17.4 \\
.423\end{array}$ & $\begin{array}{l}18.1 \\
.369\end{array}$ & $\begin{array}{l}14.8 \\
.850\end{array}$ & $\begin{array}{l}16.0 \\
.824\end{array}$ \\
\hline & 10 & $\begin{array}{l}\text { Mean } \\
\text { SE }\end{array}$ & $\begin{array}{l}12.6 \\
.897\end{array}$ & $\begin{array}{l}12.5 \\
1.13\end{array}$ & $\begin{array}{r}6.6 \\
1.10\end{array}$ & $\begin{array}{r}8.1 \\
1.18\end{array}$ & $\begin{array}{l}12.8 \\
.806\end{array}$ & $\begin{array}{l}12.4 \\
.952\end{array}$ & $\begin{array}{r}7.2 \\
.957\end{array}$ & $\begin{array}{r}7.9 \\
.760\end{array}$ & $\begin{array}{l}15.2 \\
.534\end{array}$ & $\begin{array}{l}15.1 \\
.609\end{array}$ & $\begin{array}{r}9.4 \\
1.16\end{array}$ & $\begin{array}{l}10.5 \\
.875\end{array}$ \\
\hline
\end{tabular}


the mean difference was 1.6 items, which was a significant Ranschburg effect $[F(1.84)=32.13$, $\mathrm{p}<.001]$.

\section{Relative .Measure of the Ranschburg Effect}

Jahnke (1969b) suggested that when levels of performance differ widely as a result of experimental manipulations, a relative measure of the Ranschburg effect might be more appropriate than an absolute difference measure. Jahnke suggested the formula 1 $(\mathrm{E} / \mathrm{C})$ as appropriate for this purpose. When the data for both free recall and serial position scoring were reanalyzed with this measure, it was discovered that in this experiment no important differences occurred in the pattern of results produced by the relative and absolute measures.

\section{Noncritical Items Analysis}

To determine the effect of the repeated items on recall of the other items in the sequence, separate analyses were computed for both free recall and serial position scoring. using total number correct on the noncritical items as the performance measure. In both cases. when the critical items were eliminated from the sequence the Ranschburg effect disappeared: With free recall scoring, the mean difference between recall of experimental and control sequences collapsed across both lengths was only .03 items $[\mathrm{F}(1,84)=1.55$, $\mathrm{p}>.2]$. With serial position scoring, the corresponding difference was only .01 items $[F(1,84)=.20, p>.6]$. In addition. there were no significant interactions involving the occurrence of the Ranschburg effect.

\section{DISCUSSION}

\section{General Observations about the Ranschburg Effect}

The present data support several general conclusions about the Ranschburg effect. First, as suggested by Jahnke (1969b), the data indicate that the effect is primarily a result of the repeated item's not being recalled the appropriate number of times rather than as a result of its being misplaced in recall. One is led to this conclusion by comparing the mean performance scores for the repeated and control items with free recall and serial position scoring. With free recall scoring, the mean number of repeated items correctly recalled was 31.0 . With serial position scoring, the mean was 25.2 items. This is a difference of 5.8 items. For control items, the corresponding means were 35.2 and 27.1 items, respectively, a difference of 8.1 items. Therefore, control items, not repeated items, were more likely to be misplaced in recall. Secondly, the present data agree with past evidence (e.g., Jahnke, 1969a, b) indicating that the Ranschburg effect is mainly the result of a decrement in performance for the second occurrence of the repeated item. The present study also confirms, contrary to early conceptions of the Ranschburg effect (for a review, see McGeoch, 1942) but consistent with several recent studies (e.g., Crowder, 1968a; Hinrichs et al, in press; Jahnke, 1969a, b), that the decrement in performance which defines the effect is exhibited only on the repeated items themselves. Sequences containing repeated items were recalled less well than were control sequences, but when the critical items were removed from the sequences, retention was found to be essentially the same for both experimental and control sequences.

\section{Boundary Conditions of the Ranschburg Effect}

The present experiment extended the range of conditions under which the Ranschburg effect has been examined, and the results demonstrated that the Ranschburg effect is a pervasive and robust phenomenon. Apparently, the range of values over which the present variables were manipulated are well within the boundary conditions for the phenomenon. The finding that rate of presentation did not interact with the Ranschburg effect suggests that it is the spacing between the repeated items which establishes a boundary condition for the effect and not the time interval between their presentations, as Turley's (1906) results might indicate. In addition, the Wickelgren $(1965,1966)$ suggestion that slow rates of presentation may increase the probability of detection of a repeated item, thereby increasing the probability that these items will be recalled, was not supported.

The finding that modality, rate of presentation, and sequence length did not directly influence the Ranschburg effect points out the relative insensitivity of the phenomenon to stimulus variables. As mentioned earlier, it has been demonstrated that the Ranschburg effect is primarily affected by output variables. While some stimulus variables have been effective in influencing the phenomenon, most have also had some influence in the recall process, e.g., in changing the guessing probability (Hinrichs et al, in press; Jahnke, 1972). Although the stimulus variables may not be directly effective in changing the phenomenon, one possible means by which stimulus variables may indirectly influence the Ranschburg effect is by changing the overall performance level. Changing the performance level could affect the phenomenon in three ways. First, it could produce a ceiling effect in which both experimental and control items are rarely forgotten. Secondly. it could produce a floor effect whereby neither experimental nor control items are recalled frequently. Thirdly, it could change the guessing bias towards including repeats. This might occur if, at a low level of performance, $S$ purposely repeats the few items he definitely remembers in hopes of guessing their positions correctly. In the present study, the Ranschburg effect was found with free recall scoring when control 
sequence performance ranged from $64 \%$ to almost $98 \%$ correct. Lower performance levels remain to be tested.

Serial position scoring produced a greater range of performance levels. If serial position scoring can be interpreted as merely a stricter criterion for evaluating responses, then support for the error rate hypothesis can be found. By examining the mean number correct in the critical item positions in Tables 1 and 2 , it can be observed that only serial position scoring of the 10 -item sequences produced a performance level greatly different from the rest. This was also the only condition in which no Ranschburg effect was observed. It is evident that the serial position scoring criterion alone did not eliminate the Ranschburg effect, as the effect was significant in the 7-item set. The longer sequence length alone also did not eliminate the effect, because when free recall scoring was employed, the Ranschburg effect was significant in the 10-item sequences. Apparently, then, the reduction in the Ranschburg effect was established by the low performance level resulting from the combined effect of the 10 -item sequences and the serial position scoring criterion.

\section{Evaluation of Explanatory Mechanisms for the Ranschburg Effect}

While there is some overlap among them, essentially six mechanisms for explaining the Ranschburg effect have been proposed to which the present data may be relevant (see Hinrichs et al, in press; Jahnke. 1969b; Obonai \& Tatsuno, 1954; Wickelgren, 1965, 1966). Three of these mechanisms deal with primarily input processes and three with output or recall processes. The manipulated stimulus variables alone proved to be ineffective in eliminating the Ranschburg effect, while apparently the error rate, an output factor. was effective, suggesting that in general explanatory mechanisms based upon recall processes should be preferred to input process mechanisms. For a more detailed evaluation of these mechanisms. see Hinrichs et al (in press) and Jahnke (1969b).

The present data appear to be especially consistent with the guessing bias interpretation of the Ranschburg effect suggested by Hinrichs et al (in press). They assumed that repeated and control items have equal probabilities of being forgotten but that control items have a higher probability of being guessed correctly. The hypothesis states that unless $S$ detects a repetition in the sequence, he maintains an implicit guessing bias against repeating items in recall. Consequently, whenever the repeated item is not specifically remembered, $\mathrm{S}$ guesses from the set of items not already emitted as responses (limited by S's memory of previous responses). The bias produces a low probability of guessing a repeated item correctly while yielding an optimal strategy for guessing nonrepeated items. Control item performance therefore. should normally exceed repeated item performance.
The guessing hypothesis is consistent with the present data in several respects. First, it predicts that the Ranschburg effect should be the result of the repeated item's not being recalled the appropriate number of rat ${ }_{1} s$ rather than as a result of the repeated item's being misplaced in recall. Second, it suggests that the phenomenon should be an effect involving only the repeated items and not an effect involving the noncritical items. Third, it predicts that the locus of the effect should be primarily at the second occurrence of the repeated item in recall. The Ranschburg effect would occur in the first output position only when $S$ anticipated using a specific response later in his recall sequence. Finally, the guessing interpretation would predict that stimulus variables would influence the phenomenon only if they changed the probability of detection, e.g., spacing, or if they influenced the recall process in some manner, e.g. changing the performance level or guessing probability.

According to the guessing hypothesis, unless low levels of performance do change the guessing bias or unless the set size is large, very low levels of retention might not eliminate the Ranschburg effect when free recall scoring is employed; there should always be some probability of guessing the control item, while the probability of guessing a repeated item should remain low. In fact, unless a level of performance which does change the bias is reached, the magnitude of the Ranschburg effect should increase as performance declines. This would occur because declining retention should produce more guessing, therefore allowing greater opportunity for the bias to work. In the present experiment, when free recall scoring was employed, the 10-item sequences did produce a small performance decrement especially in the later serial position. This condition also did produce a significantly larger Ranschburg effect in the second critical item position.

When serial position scoring is employed, the Ranschburg effect may be eliminated without the bias being shifted. Since the repeated items are more often omitted from a sequence than are the control items, there is a greater opportunity for control items to be misplaced in recall. Consequently, the additional number of errors produced by the stricter criterion of serial position scoring should be larger for the control items than for the repeated items. Serial position scoring. therefore, should reduce the difference between recall of repeated and control items and thereby reduce or eliminate the Ranschburg effect. The serial position scoring criterion alone. however, is not sufficient to eliminate the Ranschburg effect; instead. it is necessary that performance decline enough for misplacement errors to be prevalent. In this experiment. the Ranschburg effect was eliminated in only the 10-item sequences. Consequently, serial position scoring tends to attenuate the differences between control item and repeated item performance and may eliminate the Ranschburg effect as overall performance declines. 
suggesting an interaction between the performance level and the magnitude of the Ranschburg effect.

\section{REFERENCES}

Crowder. R. G. Intraserial repetition effects in immediate memory. Journal of Verbal Learning \& Verbal Behavior, 1968a. 7. 446-451.

Crowder, R. G. Repetition effects in immediate memory when there are no repeated elements in the stimuli. Journal of Experimental Psychology, 1968b, 78, 605-609.

Crowder. R. G.. \& Melton. A. W. The Ranschburg phenomenon: Failures of immediate recall correlated with repetition of elements within a stimulus. Psychonomic Science. 1965, 2, 295.296.

Harris. C. J.. \& Jahnke, J. C. Effect of partial recall on the Ranschburg phenomenon. Journal of Experimental Psychology, 1972, 93, 118-122.

Hinrichs. J. V.. Mewaldt, S. P., \& Redding, J. The Ranschburg effect: Repetition and guessing factors in short-term memory. Journal of Verbal Learning \& Verbal Behavior, in press.

Jahnke, J. C. Output interference and the Ranschburg effect. Journal of Verbal Learning \& Verbal Behavior, 1969a, 8, 614-621.

Jahnke. J. C. The Ranschburg effect. Psvchological Review, 1969b. 76. 592-605.

Jahnke. J. C. Probed recall of strings that contain repeated elements. Journal of Verbal Learning \& Verbal Behavior, $1970,9.450-455$.
Jahnke, J. C. The effects of intraserial and interserial repetition on recall. Journal of Verbal Learning \& Verbal Behavior. $1972,11,706-716$.

Jahnke, J. C.. \& Melton. A. W. A coustic similarity and the Ranschburg phenomenon. Proceedings of the 76 th Annual Convention of the American Psychological Association, 1968, 3, 65-66.

McGeoch. J. A. The psychology of human learning. New York: Longmans, Green, 1942.

Moses, L. E., \& Oakford, R. V. Tables of random permutations. Stanford: Stanford University Press, 1963.

Obonai, T., \& Tatsuno, C. H. Facilitation and inhibition in memorizing series of digits or letters. Japanese Psychological Research, 1954, 1, 1-8.

Turley, L. A. Inhibition and reinforcement. Harvard Psychological Studies. 1906, 2, 293-297.

Wickelgren, W. A. Short-term memory for repeated and non-repeated items. Quarterly Journal of Experimental Psychology, 1965, 17, 14-25.

Wickelgren. W. A. Associative intrusions in short-term recall. Journal of Experimental Psychology, 1966, 72, 853-858.

Wolf, T. M., \& Jahnke, J. C. The effect of intraserial repetition on short-term recognition and recall. Journal of Experimental Psychology, 1968, 77, 572-580.

(Received for publication November 9, 1972; revision received January 5,1973 .) 